\title{
Column Carving Art in Ancient Huizhou Architecture
}

\author{
Feng Li \\ (School of Art, East China University of Technology, nanchang, Jiangxi Province, China) \\ 875720874@qq.com
}

Keywords: Carving; Column Bases; Decoration; Patterns

\begin{abstract}
Unlike column base wood, furniture, porcelain, people today can add color or decoration Home Furnishing at home and admire. Unlike wood, furniture, porcelain, people today can add color or decoration Home Furnishing at home and admire. Stone plinth in modern life for the villagers have no practical significance, individual heavy and easy handling and placement, not attention, abandoned on the side. Lying in the house, courtyard miscellaneous grass base, are still under the attack of wind and rain, the passage of time quietly in the column base solidification body, as if to tell us once brilliant. The ancient Huizhou area column base sculpture buildings of Ming and Qing Dynasty in the tens of thousands of folk craftsmen from generation to generation in the world to give poor keep going by painstaking effort; It is an extremely precious cultural heritage left by the brilliant creation of the ancient working people and the accumulation of hard work. Especially in the Ming and Qing Dynasties in Huizhou, the construction of the interior environment of the language of art language in different periods of architectural pursuit. The study and analysis of it will help to understand the social situation of Huizhou during the Ming and Qing Dynasties, which is conducive to the spirit of Chinese traditional art, and is conducive to the prosperity of the Chinese nation and regional culture. It is helpful to realize the ideal of harmony between man and nature, man and man, and man himself; It is the excellent cultural tradition of China that all things are one.
\end{abstract}

\section{Introduction}

The ancient houses of Ming and Qing dynasties, Huizhou earth is the wealth of the ancestors left us. It is like a bright pearl scattered in the land of China; Ancient Huizhou is the ancient Huizhou people's ideal home, but also our spiritual lodging today. That black and white gray color of the village of simple village, white walls and green tiles, black walls, Triassic, pentagonal horse head wall, and arch, ancestral hall, temple, bridge, pagoda, pavilion, well-configured. With the hills echoes, trees and jungles, lining out the blue sky and white clouds, green water Castle, Bi wild breeze, can be described as "push the window to hear the birds sound, go out see Cui Ping Hill". Rhythmic eaves, doors and windows, carved stone carvings of exquisite decoration, the preservation of the ancient architectural complex to linger, and let us back to the time-dusty years.

In the ancient village, walk through the roadway in bluestone paved, around the courtyard of the old house or the village, we can often see a lot of abandoned stone pillars there; There are some large shape, with the base, is placed in the hall, the garden placed flowers, bonsai and other ornamental items. Column, also known as the SangZi, it has a long history, the Shang Dynasty that is used in the record. The traditional building is mainly brick and wood structure. All rely on the pillars to support the wooden beams and roofs. So there is a "wall down but house does not collapse" features. The function of the pillar is to disperse the load on the column to the larger area on the ground, and the stone pillar can be moisture-proof, the wood pillars have a certain protective effect.

The pillar is located in an important place, eye-catching, so it is often a great place to work with craftsmen. But also reflects the master of the ideal pursuit of the excellent carrier, is an important part of the construction of ancient buildings. For the stone because it is necessary to support the huge weight of the whole house wood structure; Most of the shape, beautifully decorated, old age; the main use of relief, through the carving, three-dimensional carving and other practices to the local materials, due to material for the principle of art, bluestone, black tea and tea garden stone, are commonly used stone, Material stress. Because all over the stone around Huizhou, Yixian 
Dongyuan's "Yi Qing Shi" in the north: Shexian production of "Phoenix Stone" in the east; Xi Wu junction at the junction of the precious stone stone in the south; Xiuning County West Museum of white marble gravel On the west side. Chun'an County, Zhejiang Province, green and white long "tea garden stone", as Xin'anjiang shipping convenience, has become a standing stone of Huizhou.

From today's preserved houses, ancestral hall can be seen, only the strong economic strength of the rich gentry home, ancestral hall has these Seiko gorgeous pillars. The stone craftsmen who make the stone pillar must be known locally, superb skills, good at sculpture, decorative buildings. According to local records: Shexian Qiu village Huang, Zhang, are famous for carving, since the Ming and Qing, their descendants continue to carving as a cause. Engaged in building decoration carving craftsmen are generally activities together. Huizhou merchants in the supervision of residential, in order to get the best carving decoration, usually organized two carving craftsmen to play, show skills.

Ancient Huizhou residential buildings as a result of the continuous expansion of the community, mapping the Huizhou merchants is a common purpose for the utilitarian and totem belief mentality. But because of the traditional Confucian philosophy of benevolence and morality, people as the daily life of the code of conduct, regardless of any one of the clan no matter how strong its financial resources, status prominent, back to the village, must abide by the rules. So that the traditional concept of patriarchal constitute the pattern of Huizhou architecture design restrictions, but this patriarchal concept, but also has a strong cohesion and binding.

\section{Evolution and Cultural Connotation Shape of the Column Bases}

With the Huizhou merchants flourishing period has a traditional sense of falling leaves, successful people, most people want to return home, light ancestors. As a result of home to build a house more and more people, so the formation of a comparisons of style, in size, material, indoor and outdoor decoration on the degree of luxury. This period, a unique style of sculpture art ideas and levels, from the town of style to the type of life and culture, and the type of pillar carving is also a variety of forms of development. ${ }^{[1]}$ These column bases and also houses the pattern of Feng Shui, as well as other regional style decoration and overall layout of the house complement each other, reflecting the desire and the spirit of aesthetic sentiment building owner. In the material, spiritual, prosperous, royal court, social and psychological factors under the common control of the Qing Dynasty architectural carving art has shown an unprecedented liquidity and openness. Carving gorgeous to cover the Qing Dynasty architectural art facade decoration of the atmosphere, is the social ethics and popular culture of the social spirit embodied.

The pillar engraving decoration is an important part of the overall design of the ancient Huizhou architecture. The contents of the performance are historical ancient law, myths and legends, real life, folk customs, birds and beasts, flowers and fruits. This reflects the dwelling of the attitude of life and aesthetic taste, showing the ideal living environment of a pursuit and creation, Huizhou architecture shape magnificent Qi Wei, coupled with this outdoor interior sculpture exquisite elegant design concept. Not only reflects the ancient Chinese artisans in the building of the superb skills and cultural connotation, but also gives a beautiful beauty of gorgeous. Carving art and Huizhou architecture of the perfect combination of decorative design, so that there are no traces of far-fetched, is the great achievements of traditional Chinese architecture carving art. ${ }^{[2]}$

The total column bases carving ancient Residence of design intent, based on conformal theory as the dominant ideology. Formed on the whole a rigorous layout and aesthetic philosophy, magnificent is the subject of architectural ideas, focusing on the Fan rich colorful entertainment and quiet next block, the dominant spirit of the people cultural tastes, the design has real a virtual, affectionate intentionally. In the scenery and love of the aesthetic point of view, fully embodies the Huizhou merchants' literati. Huizhou people this unique mode of thinking, the emotional and ideals in the housing ontology to form a relatively stable and differentiated common cut off, and the surrounding environment combined with the unity, so that we feel a noble and noble sense of dignity. But also reflects the Huizhou businessmen a utilitarian purpose and belief in the aesthetic.

The column from the original symbol of the town evolved into a symbolic concept, this process 
has gone through a few hundred years, the highest level of architectural art is true, natural, not the pursuit of surface rendering, only the pursuit of the environment and people feel like aura. Whether it is round carving, high relief, hollow carving, plane engraved and ideal symbol of the combination of pattern carving, as if from a unified planning and design. So far, we have lamented the houses that have fine pillars of stone carving art.

\section{The Characteristics and Aesthetics of the Column Bases}

The pillar shape is mainly drum-shaped, with melon-shaped, gourd-shaped, bottle-shaped, lotus-shaped, ancient mirror, saucer, cylindrical, square and so on. Different shapes of the column, with different meanings. Melon-shaped and from the melon-shaped evolution of the drum, bottle-shaped and derived from the bottle-shaped gourd-shaped, was widely used in buildings, the previous great relationship with the reproductive worship. Melon seeds and more seeds, breeding rapidly, favored. The gourd is even regarded as a sign of masculinity. Folk legend, after the flood, hidden in the melon to survive the brothers and sisters were forced to marry, reproduce the future generations, so the gourd respect for the ancestral spirit. Later, people turn gourd as "Fluke" in disguise and a symbol of longevity, the melon-shaped, drum-shaped, bottle-shaped, gourd-shaped stone column bases gradually stylized, eventually becoming recognized as people of all auspicious graphics. $^{[3]}$

Bottle-shaped and mirror-shaped stone pillars, according to their homonym, respectively, meaning "flat" and "static". Peaceful life is one of the goals pursued by people. Today, many buildings, still placed porcelain and mirror, its intention at a glance. There are also flat and square stone pillars. The above is round, square below, representing the day, meaning upright, and man is an integral part of nature. Six prism stone pillars, the plane projection like a turtle, meaning longevity. Eight prism mining its homophonic, meaning developed, that is, the proverb so-called "if you want to rich, not no eight." Gourd-like pomegranate-shaped. With gourd when drums, that is, take "Fu Lu" homophonic, and take "more children" auspicious, with deep cultural connotation.

Shuttle-shaped column and building foundation is another feature of the Ming Dynasty. Some houses are prominently standing with a thick and tall wooden pillars, these pillars are not the general thickness of the upper and lower, but from the beginning to the upper and lower ends of the gradually received a small spindle, so called the Shuttle-shaped column. Shuttle column by supporting the lower part of the foundation stone, which is the column bases.; If you take a little attention, you can find this Mingju pillar carving exquisite, in various forms, there are round, there are octagonal, there are round or octagonal changes in the shape of the body, but its basic shape like Is the bottom of the basin, so also known as the basin. The bottom of the basic to maintain a square, the four sides of the vertical line adduction, the square four corners chiseled under the concave arc, and not four corners of the ramp, cut into the equilateral octagonal, for the convex line and then rounded, lines full of changes. Technique concise and beautiful form of primitive simplicity. Join a shuttle between the wooden columns and column bases are very unique. According to architectural experts, this design has a shock function and protect the role of the bar.

Column carving mainly flat carving, relief, three-dimensional sculpture. The style of the Ming Dynasty column is too rough, stubborn and plain concise; The Ming Dynasty, because the wealthy pursuit of luxury living, so the plinth style is becoming complex, focus on the plot and composition, carving depth. In some square stone carvings on the plot complex, from close to the vision, before and after the perspective, level, up to about more than and 10 levels, resulting in exquisite beauty. The stone material shows rigid feeling, flowers have soft feeling; some made of lotus petals, which denotes a soft, rigid contrast, just move among force and soft. ${ }^{[4]}$ From the visible, column carved the modeling methods, such as comparative distance, size, surface, strength, density, internal and external, and so on, yet flexible. Not only that Huizhou architecture produced superb artistry, but also reflects the ancient simple dialectical thought of the information penetration method.

According to some experts, major buildings are not necessarily used complex shapes such as the base of the Ming and Qing Dynasties, the imperial palace is the ancient mirror column advocating concise, and the temple of the plinth but rich and colorful. Cangshan jade on the Fayun temple, built 
in the Southern Song Dynasty safehome years (1265 1274), has been 800 years of history. In the temple still retains some of the basic pillars engraved, very vivid. With the ancient building rubble stone carving skills, in today's society seems increasingly facing difficulties heritage. Because of the massive use of reinforced concrete today, the civil structure of the house is less and less, and these stone components have a certain occasion to adapt. This is often the traditional technology can become a decisive factor in the inheritance.

\section{Performance Column Bases Carved Decoration in the Plot Content}

The plot content mainly from the plinth decorated local customs, religious beliefs, mental interests and aesthetic ideas, has the symbolic significance of praying lucky fortune. Ancient Huizhou has a long history and profound cultural background. It has a long history of Confucianism, Taoism and Buddhism. The theme of stone works, whether it is from the aesthetic taste of art, or from the educational function, are bound to involve the Confucian ethical concept. Combination of plinth decorated with folk culture, showing the unique folk characteristics, reflects the specific historical environment, embodies the ancient Huizhou people's spiritual needs.

From the base of stone carving decoration content, can be divided into categories, like abstract classes and imagery expression language. A variety of categories, merged to form the new variety of decorative patterns, its purpose is to create a lively scene and rich composition. The contents of the plot form, by the geometric pattern of Ming Dynasty to the late Qing Dynasty to the development of opera, folklore, such as snuff bottles with pictures inside, spring fling map, a gentleman farmer map, Three Kingdoms story map. We can see the different content of the subject matter in the stone sculpture in the performance of the different meaning, deeply into the Confucian life, business, the concept of official.

(1) The Representation of Concrete Form

Most of the figurative patterns take the natural form of the natural world, and directly use the objects, such as plants, animals and objects, and other objects in life to be used alone or in combination. The symbolic meaning and extended meaning can be used to express emotion. As is often found in the decoration of the crane, the lion, bats, magpies, deer and other patterns, has its symbolic meaning, expressing a variety of themes, such as the lion playing ball, crane and deer to greet spring, magpie plum branches etc. Crane in ancient times is considered to be a bird, a symbol of longevity; bat "bat" because the sound of "blessing", a symbol of good luck. People generally use these natural animals and plants, according to their aesthetic way to meet their own strong spiritual needs, and ultimately achieve the desired safety, happiness, freedom, peace of purpose.

(2) Abstract form Beyond Natural Law

The form or through the imagination by natural objects by copying, the purification process of single abstraction. In modeling, it integrates a variety of specific image, refining features, and create a natural form of human form. Abstract class stone pattern modelling is simple and novel, not very much like the image, abstract geometry, or approximate geometric shape of a graph, or a work of art to life things, abstract patterns, the things are new pattern form to undertake or transformation and it is also a common way. Such as the image of a variety of plants is often used as a pattern in the architectural decoration. These abstract patterns through art recreation process, the aesthetic significance of the more intense. Such as the geometric pattern is extended on the base of non-realism of the abstract class, to the point line and surface elements, the idea to create a consistent patterns typical of the beauty of form principle. Like the pomegranate, peony, lotus, Hui grass, cloud, water waves, and so on in Baoshan on the plinth. Influenced by Buddhist culture, lotus is the most common. Lotus petals form is composed of lotus pattern, around to open, to form a circle of small petals, is suitable for use in a circular stone plinth. So there is a tiled floor on the back cover of lotus, overlapping lotus petals, plus carving Pozhu lotus and other style.

(3) Image form Reflects Subjective Intention

Image stone carving pattern is one or several forms of the image into a picture. Sometimes, the combination of concrete and abstract, forming a rich connotation of the image. Also with the help of straight text, legends and allusions of enlightenment, reflect the folk psychology, has a profound 
symbolic meaning.

In column engraving, direct use of text to express thoughts and feelings. Since ancient times, whether it is the supreme emperor, or the lowly poor people, "longevity" has always been a primary goal. Health and longevity, is the highest realm of spiritual yearning. Such as "Shou" and the combination of bats. There are many middle and auspicious clouds of five bats a zhuanzi "Shou" side, this is called Dr. Chen shou. One blessing: Sons and daughters. Two blessings: filial piety. Three blessings: no patient at home. Four blessings: there are no criminals in prison. Five blessings: not owe when the old time. ${ }^{[5]}$

There are a large number of people based decorative theme of the application. Among them are myths, folk tales, historical allusions and folk customs. The main characters of the plinth decorated straightaway, in addition to decorative effect, but also has certain enlightenment significance. Such as the picture called "Wish your kids a promising future" and the picture called "Snuff Bottles with Pictures Inside", is a symbol of hope children thrive expression reproductive concept. The more children the more happiness is Chinese nation's traditional concept. Such as the legend of kylin Songzi, sent the children grow up must be virtuous feudal official, to assist the country. There are customs reflect the scene a moment; some farming family, some carved a figure for the division, the purpose is to remind the children not honor the teacher and respect his teaching. This sculpture reflects the local social life and folk family fun and the people of all walks of life simple desire. At the same time, it also shows that Huizhou merchants' family is also a kind of appearance of farmers, agricultural development and commercial operation. The multi form of the image of the decorative content is further interpretation of its meaning. A single pattern is an independent content; the meaning of the connection will become a schema couplet. Decorative content clearly, isn't a density and white, rich patterns carved decoration, all vividly reveal the local residents, health and longevity, pray heaven and Kosun Kojun, family harmony, peace and prosperity of the family home, a bumper grain harvest this folk intention. In short, building plinth carved in the form, the content is to the theme of family stability and prosperity, to achieve the "figure auspicious meaning" realm. There are eight, $\mathrm{Bo} \mathrm{Gu}$, geometric shapes, text, painting like decoration, also occupy a certain position in the base pattern, ancient tripods. The organization was decorated in the fancies of men of letters or the pattern around the bottom lining, a superb collection of beautiful things, full of wit and humor.

\section{Features of the Carving Patterns of the Plinth}

From the form of carved plinth patterns, with separate patterns, patterns, patterns and suitable for continuous single piece integrated pattern, its shape and structure integrity and rigor is very strong.

(1) Separate Patterns

1. Symmetric 。Symmetrical form of composition can be divided into upper and lower symmetry, symmetry, multi-directional symmetry. It is characterized by the central axis or center as a benchmark in the upper and lower left and right sides of the same shape, the same amount of flower patterns, in order to achieve a smooth, dignified and generous, rich decorative effect.

2. Balanced type。Balanced formula is based on the gravity of the whole pattern can be arbitrary composition. Somewhat similar to the "China branch flower" composition form, not absolute symmetry, gives a dynamic, so as to create a flexible, vivid and beautiful, full of rhythm patterns, can give people the feeling of harmony and stability.

(2) Suitable Pattern and Continuous Pattern

Continuous patterns are commonly used around the stone decoration theme. Zigzag pattern is mainly used for edging or shading, neat, uniform and rich effect.

(3) Single Piece Type Integrated Pattern

The form of column base alone with two party continuous and continuous and scattered everywhere. With banana leaf, ruyi, twine, cloud and sea water pattern, multi decoration in the feet of the artifacts part. 


\section{Summary}

These subjects are used as the decoration is not only the external image of them has a certain degree of formal beauty, but also because they are able to express some thoughts, the more important is that it reflects the diversity of ancient Huizhou, comprehensive and regional characteristics of the Ming and Qing dynasties.

\section{References}

[1] Genius Craftsman - Huizhou Ancient Architecture Carving Art, Beijing Art Museum and Anhui Museum, 2014-08-01, Beijing Fine Arts Photography Press

[2] "Fish" and Its Cultural Analysis in Column Base Sculpture of Folk Houses in Bashan, Li Xianglin, 2017-07-15, Art Exploration

[3] The Artistic Form and Protection Development of Ancient Residences in Huizhou, Jiang Baofeng, Wen Jing, 2014-09-01, Hefei University of Technology Press

[4] Study on Architectural Column Art of Ming and Qing Dynasties in China, Kang Yunying, 2015-06-08, Hebei University of Science and Technology

[5] Architectural Review - Retaking Liu Dunyu's Ancient Road to Huizhou Line Series, Jin Lei, Hong Zaisheng, Gao Zhizhu, 2016-09-01, Tianjin University Press. 